\title{
IMPACTO AMBIENTAL DE LAS INCINERADORAS
}

\author{
(ENVIRONMENTAL IMPACT OF INCINERATION PLANTS)
}

José Antonio Saiz de Omeñaca, Dpto. de Silvopascicultura, E.T.S.I. de Montes. UPM

Jesús Saiz de Omeñaca, DCITTYM, Univ. de Cantabria

Fecha de recepción: 6-X-95

ESPAÑA

$113-40$

RESUMEN

La contaminación causada por las incineradoras es, potencialmente, muy importante. Conocer los riesgos ayuda a tomar decisiones para minimizar los impactos.

\section{SUMMARY}

The pollution caused by incineration plants may be considered quite substantial. It is important to know the risks in order to be able to reduce the impacts.

\section{Introducción}

El fuego no es un desconocido en el medio natural, pero la incineración artificial sí lo es en cuanto al volumen, la reiteración o las temperaturas que la caracterizan. Desde la eliminación de residuos hasta la producción de energía eléctrica, gran diversidad de procesos pueden admitir la incineración. La incineración es un tratamiento que cada vez más frecuentemente se aplica, en E.E.U.U., Japón y UE, a los residuos sólidos urbanos y el porcentaje de residuos sólidos incinerados en cada país puede variar rápidamente (en Alemania, por ejemplo, del 23\% al $38 \%$ durante solamente dos años). El cambio se ve facilitado porque la modificación de hábitos de consumo, unida a la elevación de la calidad de vida y a determinadas técnicas de ventas, ha provocado una elevación paulatina del contenido en componentes combustibles (papel, cartón, plásticos, etc.) de los residuos sólidos urbanos.

\section{2. ¿Incinerar o no incinerar?}

Independientemente de las ventajas técnicas 0 incluso medioambientales que puedan presentar, las incineraciones tienen efectos negativos para el medio ambiente: además del desprendimiento de energía en forma de calor y la formación de residuos inquemados, se pueden producir partículas, óxidos de azufre, carbono y nitrógeno, diversos hidrocarburos y otros compuestos; entre estas sustancias existen varias extremadamente peligrosas para el hombre y para el medio ambiente $(3,9)$. Frecuentemente, cuando se estiman los costes de instalación y puesta en funcionamiento de una incineradora, no se consideran los costes ambientales. Resulta, como poco, curioso el que, como la puesta en marcha de una planta incineradora no es un proyecto en el que los costes de explotación, con los precios actuales de la energía, sean positivos (los gastos en mantenimiento, amortizaciones, personal, gestión, etc., son mayores que los ingresos) haya que acudir a las necesidades sociales (se presta un servicio, que es la eliminación de residuos) como razón para la instalación de plantas incineradoras. Aún así, el punto fuerte de esta alternativa está en la posibilidad de recuperar la energía térmica de la combustión (6).

La decisión entre incinerar o no, debe tomarse tras sopesar las consecuencias ambientales de llevar a cabo o no el proceso.

Así, por ejemplo, cuando se trata de hallar la forma menos dañina de eliminar residuos sólidos urbanos se deberá 
comparar entre las consecuencias de los vertidos directos o los indirectos de distintos tipos (controlado anaeróbico, controladoanaeróbico de alta densiäad, controlado aeróbico convencional o aeróbico con trituración previa), con los efectos de la incineración o de otros procesos alternativos o complementarios, cuando sean posibles (principalmente, reciclado o/y compostaje). Este paso previo es complejo, por la gran cantidad de efectos a considerar (contaminación atmosférica; de las aguas superficiales, de infiltración y subterráneas; alteraciones locales de flora y fauna y proliferación de roedores, insectos y otros animales indeseables; deterioro de valores estéticos y paisajísticos; ocupación e inutilización del suelo, etc.) y por la necesidad de tener presentes diversos factores técnicos complementarios (minimización de impactos, drenaje de líquidos, filtrado y control de desplazamientos de gases, impermeabilizaciones, acondicionamiento de perímetros y tratamientos de lixiviados de vertederos, etc.). Si, además, se considera que en España alrededor de una tercera parte de los vertidos se realiza de forma incontrolada, con graves efectos ambientales, la eliminación de la basura en la actualidad es uno de los problemas prioritarios con los que se encuentran los municipios y comunidades autónomas, presionados por la necesidad de adoptar medidas de tratamiento y con dificultades para encontrar terrenos para los vertidos, particularmente en zonas densamente pobladas.

Los costes ambientales de la incineradoras son importantes, pero en la mayoría de los casos suelen resultar considerablemente menores que los de los vertidos. Las tecnologías de incineración han evolucionado hasta un estado en el que existe una abundante oferta de equipos que garantizan una correcta incineración de los residuos, equipos que se complementan con otros de tratamientos de gases que garantizan las emisiones de acuerdo con las normativas más estrictas, para evitar en lo posible la contaminación atmosférica. Existen tres tipos principales de técnicas de limpieza de los gases emitidos por las incineradoras, una vez filtrados (o limpiados mediante precipitadores electrostáticos): seco (se añade un reactivo seco y el producto final es un polvo seco), semi-seco (el producto es añadido en forma de una pasta y se obtiene un polvo seco) y húmedo (el gas, enfriado, es lavado y neutralizado con agua y sosa u otra solución análoga), pero en todos los casos se generan residuos problemáticos. En resumen, los costes ambientales dependientes de la tecnología de incineración (incineradores cíclicos o de alimentación continua; $y$, en este último caso, pueden ser convencionales, en lecho fluido, por infrarrojos, etc.) pueden minimizarse mediante un control adecuado de la combustión y sus productos.

La heterogeneidad, causante del aumento de diversidad de los efectos deletéreos sobre el medio ambiente, puede hacer necesaria una preclasificación, para separar el material que será encaminado a la incineradora de la que tendrá otros destinos (compostaje, reciclado, vertido de inertes).
En el caso de residuos sólidos urbanos, probablemente y al menos para grandes volúmenes, el método más aconsejable sea el reciclado y compostaje de los residuos que lo permitan, acompañado por la incineración de los rechazos que necesariamente se producen tras esta primera fase y el inevitable vertedero de apoyo para las cenizas y basuras que no se pueden reciclar, fermentar o quemar.

Mención aparte merece el carácter mutagénico (y por tanto, suele considerarse, cancerígeno) de algunas sustancias derivadas de las combustiones. La sociedad tecnológica y de consumo ha hecho y está haciendo aumentar la cantidad de tales sustancias hasta concentraciones que pueden ser muy peligrosas. Existe un explicable rechazo social hacia instalaciones como las incineradoras, que pueden ser un mal necesario, pero no hacia conductas y actitudes que son precisamente las que hacen necesario aquel mal $(0$, al menos, lo hacen crecer desmesuradamente).

\section{Contaminantes debidos a incineración}

En general, los contaminantes resultantes de las incineraciones varían según la naturaleza del combustible y son tanto más fáciles de predecir cuanto más homogéneo sea éste, como suele ocurrir en el caso de centrales térmicas convencionales (que queman gas, carbón o fuel) o de las incineradoras que queman residuos agrícolas, forestales o de una industria en particular.

En el caso opuesto podrian situarse las incineradoras de residuos sólidos urbanos, cuya naturaleza es sumamente heterogénea por naturaleza. El tipo y la cantidad de sustancias contenidas en los gases efluentes dependen principalmente de la composición de los residuos, del tipo de sistema de incineración, del control de gases y de la temperatura de incineración.

Las centrales térmicas productoras de electricidad convencionales alimentadas por gas descargan en el medio ambiente cantidades importantes de óxidos de nitrógeno, así como escasas cuantías de partículas y óxidos de azufre; las descargas de monóxido de carbono e hidrocarburos resultan despreciables. Las centrales térmicas alimentadas por fuel, más contaminantes que las de gas, desprenden escasas partículas, cantidades relativamente pequeñas de monóxido de carbono, diversos hidrocarburos y cantidades notables (aunque variables según lo haga el combustible y dependientes de las medidas de control que se tomen) de óxidos de azufre y nitrógeno. Los contaminantes originados en las centrales térmicas de carbón son, en general, más abundantes que los producidos por las centrales térmicas alimentadas por fuel, excepto quizá en lo que se refiere a hidrocarburos y óxidos de nitrógeno. Según aparece en El libro de la energía editado por el Forum Atómico Español (4), una central térmica de 1.000 Mwe de potencia, funcionando en condiciones normales y utilizando 
combustible de características medias, se supone que consume 2,3 millones de toneladas de carbón al año, con un contenido en azufre del $3,5 \%$ y con un $9 \%$ de cenizas, y que produce al año 150.000 toneladas de óxidos de azufre, 23.000 de óxidos de nitrógeno, 5.000 de partículas, 500 de hidrocarburos y 250 de monóxido de carbono'.

En el caso de las incineradoras de residuos sólidos urbanos, la caracterización resulta mucho más compleja, refleja los cambios sociales y de los hábitos de consumo y suele variar según la estación del año. El problema de la emisión de partículas, más que por éstas en sí mismas, se debe a que contienen diversas sustancias dañinas para el ambiente; entre ellas metales pesados o compuestos de metales pesados, como mercurio, cinc, cadmio, níquel, cromo y arsénico. El de los gases se debe a los ya mencionados, a otros como $\mathrm{ClH}$ y $\mathrm{FH}$ cuando la tecnología de control es insuficiente y a compuestos orgánicos peligrosos (dioxinas y furanos). En general, los gases de combustión contienen:

* partículas sólidas, con metales pesados y distintos compuestos orgánicos, clorados o no: entre un 3 y un $5 \%$ de inquemados sólidos y cenizas del combustible, con óxidos, cloruros y sulfatos, generalmente poco reactivos, de mercurio, cinc, plomo, cromo, níquel, cadmio, manganeso y arsénico, así como dioxinas, furanos y otros compuestos.

* gases ácidos: $\mathrm{ClH}$ formado a partir de PVC (policloruro de vinilo) y otros plásticos, $\mathrm{SO}_{x}$ (principalmente $\mathrm{SO}_{2}$ ) y FH, formado a partir de plásticos como el teflón, pero en una proporción entre centésimas y milésimas de la cantidad conjunta de $\mathrm{ClH}$ y $\mathrm{NO}_{\mathrm{x}}$ procedente de los combustibles, ya que la temperatura no es tan alta como para tener un origen térmico, y otros varios.

* metales en estado de vapor (mercurio, cadmio, plomo, cinc y diversos microcontaminantes, entre los que deben destacarse hidrocarburos de tipo aromáticoy derivados, clorados o no; varían según la composición de los residuos, catalizadores presentes (principalmente los citados metales pesados), precursores directos (clorofenoles, clorobencenos, etc.) o indirectos (PVC, hidrocarburos, elastómeros y otros).

Un caso particular es el de la incineración de residuos peligrosos. OPPELT ( 7 ) ofrece datos respecto a este tema, demasiado extenso para ser tratado aquí. A continuación se expone cómo los diversos contaminantes pueden afectar al

\footnotetext{
${ }^{1}$ Según la citada fuente, una central térmica de iguales características pero alimentada con 1,7 millones de metros cúbicos de combustible al año, con un contenido en azufre del 1,6\% y de cenizas del $0,05 \%$, produce $60.000 \mathrm{t}$ de óxidos $\mathrm{SO}_{x}, 25.000 \mathrm{t}$ de $\mathrm{NO}_{x}, 800 \mathrm{t}$ de partículas, $700 \mathrm{t}$ de hidrocarburos $\mathrm{y}$ tan sólo $9 \mathrm{t}$ de monóxido de carbono. si la central quema 1.900 millones de $\mathrm{m}^{3}$ (en condiciones normales de presión y temperatura), produce $15 \mathrm{t}$ de óxidos $\mathrm{SO}_{\mathrm{x}}, 13.000 \mathrm{t}$ de $\mathrm{NO}_{\mathrm{x}}$ y $500 \mathrm{t}$ de partículas.
}

hombre y a su ambiente. Puede consultarse la legislación española relativa a residuos tóxicos y peligrosos $(2,5)$ y el efecto de contaminantes sobre las plantas superiores (8).

\section{Efectos de las partículas y sustancias asociadas}

La deposición de partículas sólidas sobre las plantas entorpece la fotosíntesis y el intercambio de gases; diversas sustancias asociadas a las partículas pueden llegar a penetrar en el cuerpo de la planta, bien a través de los estomas bien por el sistema radical. Independientemente del daño que puedan causar en los organismos productores, ésta es la vía de paso de metales pesados hacia los consumidores, incluido el hombre. Las partículas sólidas en forma de polvo, se añaden al polen, esporas de hongos y bacterias y otras partículas de origen orgánico y pueden afectar directamente a los órganos respiratorios de los seres vivos e indirectamente a otros órganos, donde pueden interferir funciones vitales (envenenamientos) o actuar como agentes o de enfermedades inflamatorias. Se ha señalado la relación entre casos de cáncer y la exposición a niveles excesivos de algunos metales pesados, como el cadmio.

\section{Efectos de los óxidos de azufre, nitrógeno y carbono y sus compuestos. Efectos de los halógenos y sus derivados}

La contaminación del aire por óxidos de azufre origina perturbaciones considerables en los vegetales, reduciendo el crecimiento y las cosechas; tanto la exposición crónica como la aguda puede llegar a matar a las plantas. En los animales dificulta la respiración y puede llegar a matar a losque sufran enfermedades del aparato respiratorio. Los gases sulfurosos pueden participar en reacciones que originan productos peligrosos: ácido sulfuroso, sulfito y bisulfito, ácido sulfúrico; se ha comprobado que el bisulfito es mutagénico para, al menos, varios organismos y, por lo tanto, también el $\mathrm{SO}_{2}$, aunque este sea un mutágeno más débil.

Los óxidos de nitrógeno pueden afectar directamente a los seres vivos, pues pueden ser responsables de la formación de edemas pulmonares; además de aumentar la sensibilidad a otros agentes dañinos para los órganos respiratorios pueden ser responsables, indirectamente, de otros muchos daños, pues son sustancias que se descomponen fácilmente por la acción de la luz solar en diversos compuestos, varios de ellos muy tóxicos. Así, el $\mathrm{NO}_{2}$ reacciona con el agua y produce ácido nitroso, $\mathrm{HNO}_{2}$, que es un potente agente mutagénico. Bajo la acción de la luz, el $\mathrm{NO}_{2}$ se transforma en $\mathrm{NO}$, también mutagénico, con desprendimiento de oxígeno.

Losóxidos de carbono son los contaminantes más abundantes de la atmósfera. El monóxido de carbono es un veneno directo y acumulativo para los mamíferos (entre ellos, el hombre) y para otros grupos de animales; se ha demostrado 
experimentalmente que a concentraciones de mil partes por millón provoca intoxicaciones. El exceso de dióxido de carbono, el cual es un producto no sólo de las combustiones sino también de la respiración es quizá el principal responsable del llamado efecto invernadero y no beneficia la fotosintesis de las plantas, como quizá un poco ingenuamente podría pensarse (1). Algunos líquenes y ciertas plantas muestran tal sensibilidad que se ha propuesto su utilización como bioindicadores de contaminación atmosférica.

La lluvia ácida, cuyos efectos sobre las aguas continentales, los bosques y los cultivos son bien conocidos, es la precipitación acuosa con un $\mathrm{pH}$ inferior a 5,7, que es el normal en el agua de lluvia. La acidez se debe a la presencia de óxidos de azufre y de nitrógeno, principalmente, que se transforman en ácidos, así como de ácidos clorhídrico y fluorhídrico. El flúor y sus compuestos, tales como el ácido fluorhídrico o el fluosilícico son tóxicos para las plantas y para los animales, incluso en concentraciones muy bajas y su efecto es acumulativo a través de las cadenas tróficas; de ahí la fluorosis en el ganado.

\section{Efectos de los hidrocarburos}

Los hidrocarburos pueden reaccionar en la atmósfera con los óxidos de nitrógenoy formar sustancias responsables de irritación ocular. Entre los hidrocarburos que pueden formarse durante las incineraciones figuran hidrocarburos aromáticos policíclicos, productos químicos peligrosos desde el punto de vista de su potencial mutagénico: benzo (a) pireno, benzo (e) pireno, benzo (a) antraceno, dibenzo ( $a, h$ ) antraceno, benzo (j) fluoranteno y benzo (b) fluoranteno. Algunos de estos compuestos son mutagénicos directamente, mientras que otros son convertidos en mutágenos metabólicamente, e inducen mutaciones en cambio de fase. Ninguno de ellos son exclusivos de las incineradoras, sino que son producto común de la utilización de los combustibles, fósiles o no, en la industria, en los cigarrillos o en los automóviles.

Quizá sean las dioxinas los derivados aromáticos de las incineraciones más conocidos popularmente. $\mathrm{Su}$ popularidad se debe a una fuga de tetraclorobencenop-dioxina (producto muy tóxico y persistente) en Seveso
(Italia) en 1976 y a la agria controversia que siguió, en la que se discutieron los efectos de esta sustancia sobre los seres humanos. Los furanos son compuestos aromáticos parecidos (con un átomo de oxígeno menos en la molécula) a las dioxinas. Ambos, dioxinas y furanos se forman durante laincineración dependiendo de la naturaleza del residuo incinerado, de la presencia de catalizadores y de las condiciones de combustión (por ejemplo, la presencia de metales que actúen como catalizadores). Como las temperaturas de combustión moderadas y la abundancia de oxígeno favorecen la formación de compuestos orgánicos, se trata de disminuir la formación de hidrocarburos manteniendo ciertos niveles de temperatura e incorporando una cámara de post-combustión, medidas cuya eficacia aún se discute.

\section{BIBLIOGRAFÍA}

(1) BAZZAZ, F.A. y FAJER, E.D.: La vida de las plantas en un mundo enriquecido en $\mathrm{CO}_{2}$. Investigación y Ciencia, marzo de 1992, pp. 6-13.

(2) Boletín Oficial del Estado (Ley 20/86 de 14 de mayo). Ley Básica de Residuos Tóxicos y Peligrosos. Madrid, 1986.

(3) Dirección General del Medio Ambiente. Los residuos tóxicos y peligrosos. MOPU. Madrid, 1983

(4) Forum Atómico Español (Ed.) El libro de la energía, $3^{\text {a }}$ edición. Madrid, 1987.

(5) GARCÍA LOZANO, E.: La legislación española sobre residuos tóxicos y peligrosos. En: Residuos tóxicos y peligrosos. MOPU. Madrid, 1989.

(6) Instituto para la diversificación y ahorro de la energía (Ed.). Incineración de residuos sólidos urbanos. IDAE. Madrid, 1992.

(7) OPPELT, E.T.: Destrucción térmica de residuos peligrosos. En: Residuos tóxicos y peligrosos. MOPU. Madrid, 1989.

(8) SAIZ DE OMEÑACA, J.A.: Efectos de los contaminantes sobre las plantas superiores. Informes de la Construcción 45 (415-426): 115-121. 1993.

(9) SANZ SA, J.M.: La contaminación atmosférica. Ministerio de Obras Públicas y Transportes, 200 pp. 1991. 